RESEARCH REPORT

\title{
Neighbourhood characteristics, individual level socioeconomic factors, and depressive symptoms in young adults: the CARDIA study
}

\author{
Claire Henderson, Ana V Diez Roux, David R Jacobs Jr, Catarina I Kiefe, Delia West, \\ David R Williams
}

J Epidemiol Community Health 2005;59:322-328. doi: 10.1136/jech.2003.018846

See end of article for authors' affiliations

Correspondence to: Dr C Henderson, Public Psychiatry Fellowship, room $317,722 \mathrm{~W} 168$ th Street, New York, NY 10032, USA; hendersc@ nypdrat.cpmc.columbia.
edu

Accepted for publication 30 July 2004
Study objective: To investigate the relation between neighbourhood socioeconomic and ethnic characteristics with depressive symptoms in a population based sample.

Design: Cross sectional data from the CARDIA study, including the Center for Epidemiological Studies depression scale score (CES-D). Neighbourhoods were 1990 US census blocks of 1000 people; six census variables reflecting wealth/income, education, and occupation investigated separately and as a summary score; neighbourhood racial composition (percentage white and black) and individual level income and education were also examined.

Setting: Participants recruited in 1985/86 from community lists in Birmingham, AL; Chicago, IL; Minneapolis MN; from a health plan in Oakland, CA.

Participants: 3437 adults aged 28-40 years in 1995/96: 24\% white men, $27 \%$ white women, 20\% black men, 29\% black women.

Main results: For each race-sex group, CES-D was inversely related to neighbourhood score and individual income and education. Associations of neighbourhood score with CES-D became weak and inconsistent after adjusting for individual level factors; personal income remained strongly and inversely associated with CES-D. Age adjusted mean differences (standard errors) in CES-D between the lowest and highest income categories were 3.41 (0.62) for white men, 4.57 (0.64) for white women, 5.80 (0.87) for black men, and 5.74 (0.83) for black women. For both black and white participants, CES-D was associated negatively with percentage of white people and positively with percentage of black people in their census block, before, but not after, adjustment for individual and neighbourhood socioeconomic variables.

Conclusions: Neither neighbourhood socioeconomic characteristics nor ethnic density were consistently related to depressive symptoms once individual socioeconomic characteristics were taken into account.
$\mathrm{T}$ here has been a resurgence of research into the health effects of residential environments. ${ }^{12}$ Broadly, the hypothesis is that contextual features of residential environments may be related to health outcomes even after individual factors are taken into account. These contextual level effects may be modified by individual level factors.

Studies of area effects on mental health have used regions with populations of several million (for example, Weich et $\mathrm{al}^{3}$ and Sturm and Gresenz ${ }^{4}$ to neighbourhoods of a few thousand $^{5-7}$ and produced conflicting findings. The effects of community socioeconomic status tend to disappear after adjustment for other community level and individual level factors in some ${ }^{8-11}$ but not all studies. ${ }^{12}$

Area ethnic composition has also been studied in relation to mental health. The ethnic density hypothesis states that for persons of a given ethnicity, rates of mental disorder decrease as the percentage of persons of the same ethnicity living in the community increases. ${ }^{13}$ Protective effects have also been found for occupational ${ }^{14}$ and religious density. ${ }^{16}{ }^{17}$ The effect is proposed to be mediated through increased levels of social support and reduced levels of stress, and has been shown for psychiatric hospitalisation rates, ${ }^{18-22}$ treated rates of psychoses, ${ }^{23}$ suicide, ${ }^{6}$ non-fatal self harm, ${ }^{24}$ and common mental disorder (anxiety and depression). ${ }^{25}$ Apart from this last study, these studies did not control for individual level socioeconomic factors.
Using data from the coronary artery risk development in young adults (CARDIA) study, we investigated the relation between neighbourhood characteristics and depressive symptoms in a population based sample of young adults. We studied the effects of area socioeconomic characteristics and proportion of black and white people, taking into account individual level factors. We also examined whether these neighbourhood characteristics modify the relation between individual level socioeconomic indicators and depressive symptoms.

\section{METHODS}

CARDIA is a cohort study of cardiovascular risk factors in young adults. The sample consists of 5115 adults aged 18-30 years in 1985-86, recruited primarily through telephone contact from community lists in Birmingham, AL; Chicago, IL; and Minneapolis MN; and from membership in a prepaid health plan in Oakland, CA. ${ }^{26}$ IRB approval for the CARDIA study was obtained at each site. The goal of recruitment was to obtain at each site nearly equal numbers of black and white people, women and men, persons $<25$ and $\geqslant 25$ years of age, and persons with high school education or less and more than high school education. Cohort retention at year 10 was $79 \%$ of survivors. Year 10 data (1995-1996) were used for

Abbreviations: CARDIA, coronary artery risk development in young adults study; CES-D, Center for Epidemiological Studies depression scale 
Table 1 Socioeconomic factors, block group characteristics, and CES-D score by gender and race: the CARDIA study, 1995/ 96

\begin{tabular}{|c|c|c|c|c|}
\hline & White men $(n=830)$ & White women $(n=931)$ & Black men $(n=692)$ & Black women $(n=984)$ \\
\hline Mean age (SD) & $35.5(3.4)$ & $35.6(3.4)$ & $34.3(3.8)$ & $34.4(3.9)$ \\
\hline \multicolumn{5}{|l|}{ Income (\% distribution) } \\
\hline$<\$ 16000$ & 7.5 & 7.5 & 22.0 & 28.8 \\
\hline$\$ 16000-\$ 34999$ & 19.4 & 21.6 & 35.0 & 29.3 \\
\hline$\$ 35000-\$ 49999$ & 21.2 & 18.9 & 17.8 & 19.2 \\
\hline$\$ 50000-\$ 74999$ & 23.3 & 24.6 & 16.0 & 15.9 \\
\hline$\geqslant \$ 75000$ & 28.7 & 27.4 & 9.2 & 6.9 \\
\hline \multicolumn{5}{|l|}{ Education (\% distribution) } \\
\hline High school diploma or less & 21.7 & 17.2 & 45.8 & 36.8 \\
\hline $1-3$ years college & 21.4 & 20.9 & 31.6 & 37.7 \\
\hline 4 years college & 27.1 & 31.4 & 14.6 & 17.2 \\
\hline \multicolumn{5}{|c|}{$\begin{array}{l}\text { Block group characteristics median }(25 \text { th- } 75 \text { th } \\
\text { centile) }\end{array}$} \\
\hline Median household income ( $\$ 1000$ s) & $37.7(28.0-51.1)$ & $39.3(29.6-51.7)$ & $25.5(18.6-35.1)$ & $25.9(18.9-34.9)$ \\
\hline Median house value $(\$ 1000$ s) & $112.5(71.3-212.5)$ & $115.4(77.5-213.5)$ & $67.6(51.8-125.9)$ & $71.5(51.4-126.5)$ \\
\hline Percentage earning interest income & $53(41-63)$ & $52(41-63)$ & $28(15-42)$ & $27(15-41)$ \\
\hline Percentage complete high school & $90(81-95)$ & $90(82-95)$ & $76(64-87)$ & $74(63-85)$ \\
\hline Percentage complete college & $34(19-50)$ & $34(19-51)$ & $16(8.1-27)$ & $14(7.5-25)$ \\
\hline Percentage executive, managerial occupation & $36(25-48)$ & $36(25-48)$ & $22(14-31)$ & $21(14-31)$ \\
\hline Neighbourhood score & $4.7(1.3-8.2)$ & $5.0(1.7-8.3)$ & $-0.60(-3.7-2.7)$ & $-0.74(-3.7-2.3)$ \\
\hline Percentage black & $2.2(0.57-6.6)$ & $2.1(0.74-6.8)$ & $42(11-81)$ & $48(12-86)$ \\
\hline Percentage white & $93(83-97)$ & $92(80-96)$ & $42(11-78)$ & $35(8-76)$ \\
\hline Mean neighbourhood score (SD) & $4.8(4.7)$ & $4.9(4.5)$ & $-0.3(4.4)$ & $-0.4(4.4)$ \\
\hline CES-D score mean (SD) & 8.9 (6.7) & $9.6(7.5)$ & $11.3(8.0)$ & $12.9(9.5)$ \\
\hline Percentage 16 or more & 13.9 & 17.7 & 23.7 & 31.8 \\
\hline
\end{tabular}

these analyses because earlier addresses were not available for geocoding. Participants were then aged 28-40 years and likely to have completed their education; $68 \%$ of participants remained at their original site, with the remaining $32 \%$ were dispersed over 45 US states.

Depressive symptoms were assessed using the Center for Epidemiological Studies depression scale (CES-D), an extensively used instrument with well studied psychometric properties $^{27}$ ); a higher score indicates more depressive symptoms, with 16 usually used as cut off point. Item frequency was ascertained over the week preceding the CARDIA year 10 examination.

Key independent variables included individual level socioeconomic indicators and neighbourhood characteristics. Participants were asked to select their total combined family income from a list of categories, and to report the highest grade or year of school completed. We categorised income into five groups (under \$16 000; 16 000-34 999;

Table 2 Age adjusted mean differences in CES-D scores by individual level socioeconomic indicators and neighbourhood summary socioeconomic score

\begin{tabular}{|c|c|c|c|c|}
\hline & White men & White women & Black men & Black women \\
\hline \multicolumn{5}{|l|}{ Individual level income $†$} \\
\hline$<16000$ & & & $5.80(0.87)$ & $5.74(0.83)$ \\
\hline $16000-34999$ & $3.41(0.62)$ & $4.57(0.64)$ & $2.90(0.78)$ & $3.27(0.83)$ \\
\hline $35000-49999$ & $1.80(0.66)$ & $1.67(0.71)$ & $1.31(0.92)$ & $2.17(0.92)$ \\
\hline $50000-74999$ & $1.28(0.64)$ & $1.52(0.66)$ & Reference & reference \\
\hline $75000+$ & Reference & Reference & & \\
\hline $\mathrm{p}$ trend across categories* & 0.0001 & 0.0001 & 0.0001 & 0.0001 \\
\hline $\begin{array}{l}\text { Mean difference per unit increase in income } \\
\text { category } \ddagger\end{array}$ & $-1.08(0.20)$ & $-1.45(0.20)$ & $-1.86(0.27)$ & $-1.84(0.26)$ \\
\hline \multicolumn{5}{|l|}{ Individual level education } \\
\hline High school diploma or less & $1.59(0.65)$ & $3.45(0.73)$ & $4.32(1.15)$ & $5.48(1.14)$ \\
\hline $1-3$ years college & $0.81(0.66)$ & $1.26(0.70)$ & $1.81(1.19)$ & $2.32(1.14)$ \\
\hline 4 years college & $-0.16(0.61)$ & $0.56(0.62)$ & $-0.24(1.32)$ & $1.20(1.25)$ \\
\hline Some graduate school & Reference & Reference & Reference & Reference \\
\hline $\mathrm{p}$ trend across categories* & 0.0074 & 0.0001 & 0.0001 & 0.0001 \\
\hline $\begin{array}{l}\text { Mean difference per unit increase in } \\
\text { education category } \ddagger\end{array}$ & $-0.56(0.21)$ & $-1.05(0.23)$ & $-1.82(0.32)$ & $-1.97(0.32)$ \\
\hline \multicolumn{5}{|l|}{$\begin{array}{l}\text { Race specific quartiles of neighbourhood } \\
\text { score }\end{array}$} \\
\hline Q1: Lowest & $1.99(0.65)$ & $2.88(0.70)$ & $2.80(0.85)$ & $2.23(0.86)$ \\
\hline Q2 & $0.68(0.66)$ & $1.73(0.69)$ & $2.33(0.85)$ & $0.98(0.86)$ \\
\hline Q3 & $0.60(0.66)$ & $1.25(0.68)$ & $1.21(0.85)$ & $0.12(0.86)$ \\
\hline Q4: Highest & Reference & Reference & reference & reference \\
\hline $\mathrm{p}$ trend across quartiles* & 0.0034 & 0.0001 & 0.0004 & 0.0053 \\
\hline $\begin{array}{l}\text { Mean difference per unit increase in } \\
\text { neighbourhood score }\end{array}$ & $-0.16(0.05)$ & $-0.21(0.05)$ & $-0.23(0.07)$ & $-0.18(0.07)$ \\
\hline
\end{tabular}


35 000-49 999; 50 000-74 999, 75000 or more). Because of small numbers, the two lowest categories were combined in white participants, and the two highest combined in black participants. Education was categorised as high school diploma or less; one to three years of college, four years of college, some graduate or professional school.

Census defined block groups were used as proxies for neighbourhoods. On average, each block group includes about 1000 people. Study participants' home addresses were linked to their block group by a geocoding firm. Six area variables collected by the US Bureau of the Census in 1990 reflecting wealth/income (median household income, median value of housing units, and percentage of households receiving interest, dividend, or net rental income), education (percentage adults with complete high school, percentage adults with complete college), and occupation (percentage of persons in managerial or professional specialty occupations) were investigated. These variables were also combined into a summary score. Because of their skewed distribution, median household income and median value of housing units were log transformed before the construction of the score. For each of the census variables a $\mathrm{Z}$ score was estimated by subtracting the mean and dividing by the standard deviation; $\mathrm{Z}$ scores were then summed to get a neighbourhood summary score, with increasing neighbourhood score signifying increasing neighbourhood advantage. ${ }^{28}$ Neighbourhood scores ranged from -11.4 to 17.4. There were important racial differences in neighbourhood characteristics that would result in little overlap if common categories were used, so block groups were categorised into race specific quartiles of participants based on the block group summary score. Neighbourhood racial composition (percentage white and percentage black) was also investigated.
Of the CARDIA participants who attended the year 10 follow up, $89 \%$ (3531) were matched to block group data. Of these, 94 participants were excluded because of missing income or education $(n=43)$ or depression score $(n=51)$, leaving 3437 subjects available for analyses. These participants were distributed in 2451 block groups. About $78 \%$ of participants were in block groups with only one participant; only $2 \%$ were in block groups with five participants or more.

\section{Statistical methods}

Because of important differences in CES-D scores by sex and race, all analyses were stratified by these two variables. Age adjusted mean differences in CES-D scores by individual level socioeconomic indicators and race-specific quartiles of neighbourhood score and racial composition were estimated using linear regression. The $\mathrm{p}$ values for trend were obtained by including categories as an ordinal covariate in regression equations. Neighbourhood scores and individual level variables were investigated as both categorical and continuous variables. Interactions between neighbourhood scores and individual level variables were investigated using stratified analyses and tested by including appropriate interaction terms. If no interactions were present, multiple regression was used to estimate mean differences by neighbourhood categories before and after adjustment for personal socioeconomic indicators. This was repeated for each neighbourhood score component. For components reflecting neighbourhood income or education level, multiple regression adjusting only for the individual level equivalent along with age was also performed. Similarly, multiple regression was used to estimate mean difference in CES-D score by categories of neighbourhood ethnic composition before and after adjustment for personal and neighbourhood

Table 3 Age adjusted mean differences in CES-D score per unit increase in neighbourhood score stratified by income and education

\begin{tabular}{|c|c|c|}
\hline & White men & White women \\
\hline & $\begin{array}{l}\text { Mean difference per unit increase } \\
\text { in neighbourhood score }\end{array}$ & $\begin{array}{l}\text { Mean difference per unit increase in } \\
\text { neighbourhood score }\end{array}$ \\
\hline \multirow[t]{3}{*}{$\begin{array}{l}\text { Individual level income } \\
<\$ 49999 \\
\geqslant \$ 50000 \\
p \text { value for interaction* }\end{array}$} & $\begin{array}{l}-0.30(0.33) \\
-0.28(0.30) \\
0.96\end{array}$ & $\begin{array}{l}-0.07(0.34) \\
-0.94(0.32) \\
0.06\end{array}$ \\
\hline & Black men & Black women \\
\hline & $\begin{array}{l}\text { Mean difference per unit increase } \\
\text { in neighbourhood score }\end{array}$ & $\begin{array}{l}\text { Mean difference per unit increase in } \\
\text { neighbourhood score }\end{array}$ \\
\hline \multirow[t]{3}{*}{$\begin{array}{l}\text { Individual level income } \\
<\$ 34999 \\
\geqslant \$ 35000 \\
p \text { value for interaction* }\end{array}$} & $\begin{array}{l}-0.04(0.37) \\
-1.07(0.42) \\
0.07\end{array}$ & $\begin{array}{l}-0.34(0.36) \\
-0.44(0.43) \\
0.86\end{array}$ \\
\hline & White men & White women \\
\hline & $\begin{array}{l}\text { Mean difference per unit increase } \\
\text { in neighbourhood score }\end{array}$ & $\begin{array}{l}\text { Mean difference per unit increase in } \\
\text { neighbourhood score }\end{array}$ \\
\hline \multirow[t]{3}{*}{$\begin{array}{l}\text { Individual level education } \\
\text { Up to } 3 \text { years college } \\
4 \text { years college or more } \\
\text { p value for interaction* }\end{array}$} & $\begin{array}{l}-0.60(0.33) \\
-0.43(0.28) \\
0.70\end{array}$ & $\begin{array}{l}-1.21(0.40) \\
-0.44(0.29) \\
0.12\end{array}$ \\
\hline & Black men & Black women \\
\hline & $\begin{array}{l}\text { Mean difference per unit increase } \\
\text { in neighbourhood score }\end{array}$ & $\begin{array}{l}\text { Mean difference per unit increase in } \\
\text { neighbourhood score }\end{array}$ \\
\hline $\begin{array}{l}\text { Individual level education } \\
\text { High school or less } \\
\text { Any college or more } \\
\text { p value for interaction* }\end{array}$ & $\begin{array}{l}-0.82(0.40) \\
-0.60(0.36) \\
0.69\end{array}$ & $\begin{array}{l}-0.72(0.45) \\
-0.51(0.33) \\
0.71\end{array}$ \\
\hline
\end{tabular}


Table 4 Age adjusted mean differences in CES-D scores by individual level socioeconomic indicators and block group characteristics before and after adjustment for each other. White people

\begin{tabular}{|c|c|c|c|c|c|c|}
\hline & \multicolumn{3}{|l|}{ White men } & \multicolumn{3}{|l|}{ White women } \\
\hline & $\begin{array}{l}\text { Model with age, } \\
\text { neighbourhood } \\
\text { score+ education }\end{array}$ & $\begin{array}{l}\text { Model with age, } \\
\text { neighbourhood } \\
\text { score + income }\end{array}$ & $\begin{array}{l}\text { Model with age, } \\
\text { neighbourhood } \\
\text { score }+ \text { income }+ \\
\text { education }\end{array}$ & $\begin{array}{l}\text { Model with age, } \\
\text { neighbourhood } \\
\text { score+ education }\end{array}$ & $\begin{array}{l}\text { Model with age, } \\
\text { neighbourhood } \\
\text { score + income }\end{array}$ & $\begin{array}{l}\text { Model with age, } \\
\text { neighbourhood score } \\
+ \text { income + education }\end{array}$ \\
\hline \multicolumn{7}{|l|}{$\begin{array}{l}\text { Race specific quartiles of } \\
\text { neighbourhood score }\end{array}$} \\
\hline Q1: Lowest & $1.64(0.68)$ & $0.65(0.71)$ & $0.53(0.73)$ & $2.08(0.73)$ & $0.97(0.76)$ & $0.61(0.78)$ \\
\hline Q2 & $0.48(0.67)$ & $-0.23(0.69)$ & $-0.29(0.70)$ & $1.16(0.71)$ & $0.74(0.71)$ & $0.48(0.72)$ \\
\hline Q3 & $0.41(0.67)$ & $0.08(0.67)$ & $0.02(0.67)$ & $0.94(0.69)$ & $0.56(0.69)$ & $0.42(0.69)$ \\
\hline Q4: Highest & Reference & Reference & Reference & reference & reference & reference \\
\hline $\begin{array}{l}\text { p trend across quartile* } \\
\text { Individual level incomet } \\
\end{array}$ & 0.02 & 0.4 & 0.6 & 0.006 & 0.2 & 0.4 \\
\hline $16000-34999$ & & $3.20(0.68)$ & $3.12(0.70)$ & & $4.16(0.71)$ & $3.79(0.73)$ \\
\hline $35000-49999$ & & $1.69(0.71)$ & $1.62(0.72)$ & & $1.36(0.75)$ & $1.12(0.76)$ \\
\hline 50000-74999 & & $1.21(0.66)$ & $1.21(0.69)$ & & $1.30(0.69)$ & $1.20(0.69)$ \\
\hline $75000+$ & & Reference & Reference & & reference & Reference \\
\hline p trend across categories* & & 0.0001 & 0.0001 & & 0.0001 & 0.0001 \\
\hline High school diploma or less & $1.12(0.68)$ & & $0.57(0.69)$ & $2.80(0.77)$ & & $2.00(0.77)$ \\
\hline $1-3$ years college & $0.47(0.67)$ & & $-0.05(0.68)$ & $0.78(0.72)$ & & $0.36(0.71)$ \\
\hline 4 years college & $-0.37(0.62)$ & & $-0.62(0.62)$ & $0.42(0.62)$ & & $0.34(0.61)$ \\
\hline Some graduate school & Reference & & Reference & reference & & Reference \\
\hline $\mathrm{p}$ trend across categories* & 0.06 & & 0.3 & 0.0007 & & 0.02 \\
\hline
\end{tabular}

socioeconomic characteristics. As the distributions of CES-D scores were slightly positively skewed, the analyses were repeated after a $\log$ transformation. Because nearly $80 \%$ of participants were in block groups with only one subject and only $2 \%$ were in block groups with five subjects or more, no special methods were necessary to account for the clustering.

We used the continuous form of the CES-D score as a measure of depressive symptoms, rather than the cut off point of 16 used to screen for major depressive disorder, because of the better sensitivity of continuous data. ${ }^{25}$ However, we reran final adjusted models for neighbourhood socioeconomic score and ethnic composition using a CES-D score dichotomised at 16 and found qualitatively similar results (data not shown).

\section{RESULTS}

The study population was $56 \%$ female, with similar numbers of white and black women but rather more white compared with black men (table 1). Mean ages for the four groups ranged from 34.3 (black men) to 35.6 (white women). Black men and women earned substantially less than their white counterparts, $(\mathrm{p}<0.001$ for both genders $)$ and had received

Table 5 Age adjusted mean differences in CES-D scores by individual level socioeconomic indicators and neighbourhood characteristics before and after adjustment for each other. Black people

\begin{tabular}{|c|c|c|c|c|c|c|}
\hline & \multicolumn{3}{|l|}{ Black men } & \multicolumn{3}{|l|}{ Black women } \\
\hline & $\begin{array}{l}\text { Model with age, } \\
\text { neighbourhood } \\
\text { score+ education }\end{array}$ & $\begin{array}{l}\text { Model with age, } \\
\text { neighbourhood } \\
\text { score + income }\end{array}$ & $\begin{array}{l}\text { Model with age, } \\
\text { neighbourhood } \\
\text { score + income + } \\
\text { education }\end{array}$ & $\begin{array}{l}\text { Model with age, } \\
\text { neighbourhood } \\
\text { score+ education }\end{array}$ & $\begin{array}{l}\text { Model with age, } \\
\text { neighbourhood } \\
\text { score + income }\end{array}$ & $\begin{array}{l}\text { Model with age, } \\
\text { neighbourhood } \\
\text { score + income + } \\
\text { education }\end{array}$ \\
\hline \multicolumn{7}{|l|}{$\begin{array}{l}\text { Race specific quartiles of } \\
\text { neighbourhood score }\end{array}$} \\
\hline Q1: Lowest & $1.89(0.85)$ & $1.12(0.89)$ & $0.92(0.88)$ & $1.37(0.87)$ & $0.50(0.89)$ & $0.28(0.89)$ \\
\hline Q2 & $1.59(0.84)$ & $0.87(0.87)$ & $0.72(0.86)$ & $0.29(0.86)$ & $-0.40(0.87)$ & $-0.57(0.87)$ \\
\hline Q3 & $0.98(0.84)$ & $0.55(0.84)$ & $0.55(0.84)$ & $-0.34(0.85)$ & $-0.64(0.86)$ & $-0.81(0.86)$ \\
\hline Q4: Highest & Reference & Reference & Reference & reference & reference & reference \\
\hline $\begin{array}{l}p \text { trend across quartiles* } \\
\text { Individual level incomet }\end{array}$ & 0.02 & 0.2 & 0.3 & 0.08 & 0.5 & 0.6 \\
\hline$<16000$ & & $5.38(0.93)$ & $4.18(1.00)$ & & $5.62(0.88)$ & $4.35(0.93)$ \\
\hline $16000-34999$ & & $2.56(0.82)$ & $1.90(0.85)$ & & $3.18(0.86)$ & $2.67(0.87)$ \\
\hline $35000-49999$ & & $1.14(0.93)$ & $0.92(0.93)$ & & $2.15(0.94)$ & $1.92(0.93)$ \\
\hline $50000-74999$ & & Reference & Reference & & reference & Reference \\
\hline \multicolumn{7}{|l|}{$75000+$} \\
\hline $\begin{array}{l}p \text { trend across categories* } \\
\text { Individual level education }\end{array}$ & & 0.0001 & 0.0001 & & 0.0001 & 0.0001 \\
\hline High school diploma or less & $3.79(1.17)$ & & $2.25(1.22)$ & $5.19(1.17)$ & & $3.63(1.20)$ \\
\hline $1-3$ years college & $1.45(1.20)$ & & $0.81(1.20)$ & $2.06(1.16)$ & & $1.20(1.17)$ \\
\hline 4 years college & $-0.41(1.32)$ & & $-0.76(1.31)$ & $1.11(1.26)$ & & $0.74(1.26)$ \\
\hline Some graduate school & Reference & & Reference & reference & & Reference \\
\hline$p$ trend across categories* & 0.0001 & & 0.002 & 0.0001 & & 0.0001 \\
\hline
\end{tabular}


less education ( $\mathrm{p}<0.001$ for both). Mean block group scores were similar for men and women of each ethnic group but were higher for white people compared with black people $(\mathrm{p}<0.0001$ for both) signifying that white people tended to live in significantly better off neighbourhoods. White men and women lived in predominantly white neighbourhoods (medians $93 \%$ and $92 \%$ respectively, with interquartile ranges $80 \%-97 \%$ ), while for the black population the percentage of black people in the neighbourhood was much more variable (median of $42 \%$ for men and $48 \%$ for women, with interquartile ranges $11 \%-86 \%)$. CES-D scores were significantly higher in black people than in white people among both men and women (both $\mathrm{p}<0.0001$ ). CES-D scores were higher in women than in men for black people $(p=0.0002)$, but this was less clear for their white counterparts $(p=0.05)$. As previously reported, ${ }^{28}$ both income and education are correlated with neighbourhood score for black and white people. In these analyses, Spearman correlation coefficients between the income and education categories and the neighbourhood score ranged from 0.22 to 0.45 , low enough to estimate their independent effects.

While there were significant trends in mean CES-D scores across categories of individual income, education, and neighbourhood score (table 2), differences in score between the top and bottom categories were usually greater for the income and education categories than for the neighbourhood score categories. To further investigate whether associations of neighbourhood score with depressive symptoms were similar across categories of individual level income and education we estimated mean differences in CES-D per unit increase in neighbourhood score by categories of individual level income and education (table 3). We stratifed using approximate median splits for each individual level variable. Although the interactions were marginally significant for black men and white women, there was no clear evidence for an interaction on an additive scale between the effect of neighbourhood on CES-D score and either individual income or education.

In tables 4 and 5, each column gives adjusted mean differences in CES-D scores corresponding to a separate model including age and the neighbourhood and personal socioeconomic variables for which estimates are shown. Results were similar after log transformation of CESD score (data not shown). The effect of neighbourhood seems either weak, when adjustment for education is made, or nonexistent, once adjustment for individual income is made. However, the effects of education (except for white men) and individual income persist after adjustment for each other and for neighbourhood score. The largest differences in mean CES-D score between the top and bottom categories are observed for income. Similar results to those for neighbourhood score were obtained when its components were investigated separately and adjusted for the corresponding individual level indicator (data not shown).

In both ethnic groups, after adjustment for age, CES-D scores decrease with decreasing percentage black in the block group and increase with decreasing percentage white (table 6). These differences are reduced after adjustment for individual level income and education and disappear after additional adjustment for neighbourhood score, with the exception of white women and possibly white men, among whom the inverse association with percentage white people persists after adjustment. For black men, the direction of the association seems to be reversed after adjustment, but this inverse association was not statistically significant. When adjusting only for age and neighbourhood score (results not shown), differences persist for percentage white for white men and women, and percentage black for white and black men. For white people, the analysis was repeated using two categories because of the small ranges involved (results not shown). For percentage black, the highest quartile was compared with the three lower ones; for percentage white, the lowest quartile was compared with the rest. Again, only the inverse relation with percentage white for women persists after adjustment (an increase in CES-D score of 1.27 (95\% CI 0.19 to 2.34) for the lowest quartile of percentage white compared with the rest.) When we reran our final adjusted models using a CES-D score dichotomised at 16, we found qualitatively similar results (data not shown).

\section{DISCUSSION}

Among all four race sex groups, but most noticeably for black men and women, CES-D score was inversely related to individual income, education (all assessed in 1995-96), and neighbourhood score (assessed using address in 1995-96 and census data in 1990). In addition, CES-D score was negatively associated with percentage white block group composition and positively with percentage black composition. However,

Table 6 Adjusted mean differences in CES-D scores by block group racial composition before and after adjustment for individual level income, education, and neighbourhood score

\begin{tabular}{|c|c|c|c|c|c|c|c|c|}
\hline & \multicolumn{2}{|l|}{ White men } & \multicolumn{2}{|l|}{ White women } & \multicolumn{2}{|l|}{ Black men } & \multicolumn{2}{|l|}{ Black women } \\
\hline & $\begin{array}{l}\text { Adjusted for } \\
\text { age }\end{array}$ & $\begin{array}{l}\text { Age }+ \text { income, } \\
\text { education, and } \\
\text { neighbourhood } \\
\text { score }\end{array}$ & $\begin{array}{l}\text { Adjusted } \\
\text { for age }\end{array}$ & $\begin{array}{l}\text { Age }+ \text { income, } \\
\text { education, and } \\
\text { neighbourhood } \\
\text { score }\end{array}$ & $\begin{array}{l}\text { Adjusted } \\
\text { for age }\end{array}$ & $\begin{array}{l}\text { Age }+ \text { income, } \\
\text { education, and } \\
\text { neighbourhood } \\
\text { score }\end{array}$ & $\begin{array}{l}\text { Adjusted } \\
\text { for age }\end{array}$ & $\begin{array}{l}\text { Age }+ \text { income, } \\
\text { education, and } \\
\text { neighbourhood } \\
\text { score }\end{array}$ \\
\hline $\begin{array}{l}\text { Race specific quartiles } \\
\text { of percentage black } \\
\text { Q1: Lowest } \\
\text { Q2 } \\
\text { Q3 } \\
\text { Q4: Highest } \\
\text { p trend across quartiles* }\end{array}$ & $\begin{array}{l}-1.22(0.64) \\
-1.41(0.68) \\
-0.02(0.65) \\
\text { Reference } \\
0.01\end{array}$ & $\begin{array}{l}-0.61(0.65) \\
-0.61(0.69) \\
0.64(0.66) \\
\text { Reference } \\
0.12\end{array}$ & $\begin{array}{l}-1.04(0.71) \\
-1.43(0.67) \\
-0.30(0.70) \\
\text { Reference } \\
0.05\end{array}$ & $\begin{array}{l}-0.24(0.70) \\
-0.64(0.68) \\
0.06(0.70) \\
\text { Reference } \\
0.5\end{array}$ & $\begin{array}{l}-1.62(0.87) \\
-0.87(0.88) \\
-0.73(0.88) \\
\text { Reference } \\
0.07\end{array}$ & $\begin{array}{l}0.52(1.09) \\
0.40(0.99) \\
0.15(0.91) \\
\text { Reference } \\
0.6\end{array}$ & $\begin{array}{l}-1.50(0.85) \\
-0.05(0.85) \\
-0.51(0.84) \\
\text { Reference } \\
0.1\end{array}$ & $\begin{array}{l}-0.09(1.08) \\
0.82(0.98) \\
0.59(0.91) \\
\text { Reference } \\
0.9\end{array}$ \\
\hline $\begin{array}{l}\text { Race specific quartiles } \\
\text { of percentage white } \\
\text { Q1: Lowest } \\
\text { Q2 } \\
\text { Q3 } \\
\text { Q4: Highest } \\
\text { p trend across quartiles } †\end{array}$ & $\begin{array}{l}1.80(0.66) \\
0.76(0.65) \\
0.41(0.63) \\
\text { Reference } \\
0.006\end{array}$ & $\begin{array}{l}1.27(0.66) \\
0.81(0.65) \\
0.47(0.63) \\
\text { Reference } \\
0.05\end{array}$ & $\begin{array}{l}2.29(0.69) \\
0.86(0.69) \\
0.72(0.71) \\
\text { Reference } \\
0.001\end{array}$ & $\begin{array}{l}1.66(0.68) \\
0.68(0.68) \\
0.49(0.70) \\
\text { Reference } \\
0.02\end{array}$ & $\begin{array}{l}1.69(0.87) \\
0.96(0.86) \\
0.82(0.84) \\
\text { Reference } \\
0.06\end{array}$ & $\begin{array}{l}-0.25(1.11) \\
-0.19(0.94) \\
0.19(0.84) \\
\text { Reference } \\
0.8\end{array}$ & $\begin{array}{l}1.93(0.85) \\
0.33(0.86) \\
1.28(0.87) \\
\text { Reference } \\
0.07\end{array}$ & $\begin{array}{l}1.14(1.06) \\
0.45(0.90) \\
1.08(0.86) \\
\text { Reference } \\
0.4\end{array}$ \\
\hline
\end{tabular}




\section{Key points}

- Area ethnic composition has been found to be related to mental health, such that, for persons of a given ethnicity, rates of mental disorder decrease as the percentage of persons of the same ethnicity living in the community increases.

- The results of studies on neighbourhood socioeconomic status and mental health have been more conflicting.

- Neither neighbourhood socioeconomic characteristics nor ethnic density were consistently related to depressive symptom score once individual income and education were taken into account.

associations of neighbourhood score with depressive symptoms were weak and inconsistent after adjustment for individual level socioeconomic indicators. Associations of racial composition with CES-D largely disappeared after controlling for individual and neighbourhood socioeconomic variables. There was no evidence of interaction between neighbourhood and personal socioeconomic indicators.

Our findings with respect to neighbourhood socioeconomic context are consistent with two other recent studies. Reijneveld and Schene ${ }^{10}$ found a significant association of neighbourhood socioeconomic status with mental disorder, as measured by increased general health questionnaire score, when controlling for education or occupation, but this disappeared after adjustment for individual level income. Yen and Kaplan' found that residence in a poverty area was related to higher incidence of depressive symptoms but this effect disappeared after controlling for individual level confounders including income and education. These findings regarding depressive symptoms stand in contrast with the relations found between area socioeconomic status and both coronary heart disease and its risk factors. ${ }^{30-38}$

Our results do not confirm a possible causal link between neighbourhood ethnic density and depressive symptoms in American white or black young adults. Percentage black was positively related with CES-D scores and percentage white was inversely related to CES-D scores in both white and black participants, but these associations disappeared after adjustment. These patterns suggest that the observed associations are attributable to confounding by neighbourhood and individual level socioeconomic indicators. However, if as Halpern $^{13}$ suggests, the effects of ethnic density on mental illness only become apparent when group density falls below a critical mass (perhaps 40\%), the distribution of ethnic density seen in our data may not have allowed us to detect true ethnic density effects in white people, who showed high residential segregation. In black people, median ethnic density for the lowest and highest quartiles of percentage black in neighbourhoods were $4 \%$ and $98 \%$, suggesting that the range was appropriate to detect a contextual effect.

An important limitation of our study (and of others focusing on neighbourhood deprivation) is that aggregate

\section{Policy implications}

- Both national and local interventions to reduce the prevalence of depressive symptoms should focus on people with low personal education and income.

- Further study of the effects neighbourhood level factors on depression is needed. census block socioeconomic characteristics may be a poor proxy for the specific features of residential environments that are relevant to mental health. Physical and social characteristics, both objective and perceived, have been hypothesised to be relevant to the mental health of residents $^{39-41}$ but census block characteristics may not adequately capture these. The size of the geographical area potentially relevant to mental health outcomes remains unresolved. Future work with specific hypotheses regarding the processes involved may need to investigate areas of varying sizes.

Our analyses were limited to persons still participating in the CARDIA study at year 10. Potential retention bias cannot be directly tested with available data. Although year 10 follow up rates were slightly lower for black participants and for persons of low education, differences were small. While year 10 participants are likely to be healthier, this would only bias our estimates if retained persons are selected on the basis of both health status and neighbourhood characteristics. With respect to external validity, the CARDIA sample generalises only roughly to a broader population of $28-40$ year olds because of the aim to recruit approximately equal numbers by age, sex, and race and the restriction to four urban areas. While it would have been interesting to test for interactions between neighbourhood and individual characteristics and original recruitment site, such interactions were not tested because many participants had moved by year 10 .

Our study linked individual data collected in 1995-1996 to census data collected in 1990. Unfortunately census data for 1995 were not available. We believe the 1990 data are a reasonable approximation to the census tracts in which participants resided in 1995-1996. Because study participants were not clustered in neighbourhoods (there was usually only one participant per census tract) we were not able to apply multilevel modelling techniques to estimate the percentage of variance in CES-D that is between and within neighbourhoods. However, the limitations of using this type of variance decomposition exercise to draw inferences regarding causal neighbourhood effects have been repeatedly noted. ${ }^{42-44}$ In addition, as discussed by Snijders and Bosker, ${ }^{45}$ the power to detect the fixed effects of group level variables (which was our main interest in this paper) is actually maximised by sampling many groups with few people. Lastly, the correlations between neighbourhood score and individual income and education is only in the range of 0.2-0.4. Therefore we do not believe the sample design of our study is likely to have seriously hindered our ability to detect neighbourhood effects, although their precision would have been increased by a larger number of people per block through the reduced effect of confounding between area and individual characteristics. On the other hand, the misspecification of neighbourhoods and the absence of direct measures of the neighbourhood level variables of interest is undoubtedly an important limitation, and could explain our negative results.

In addition, further study of the effect of neighbourhood level factors would benefit from data on address changes to account for length of residence in a given neighbourhood. These types of analyses require residential mobility data for CARDIA, which are not available at this time. More longitudinal designs on the effect of changes to neighbourhoods are also desirable, such as the work of Dalgard and Tambs, ${ }^{46}$ which showed a relation between improvements in the environment of one area and in the mental health of its residents.

As previously reported, ${ }^{28}$ the range of neighbourhood characteristics (in both socioeconomic status and ethnic composition) differed substantially between white and black 
participants, making direct comparisons difficult and resulting in the need to use race specific categories. Thus any race differences in the associations need to be interpreted bearing in mind that what is being compared is the effect of area level deprivation and racial composition on depressive symptoms relative to members of the same ethnic group.

In summary, in this bi-ethnic sample of urban US adults, we found small and often inconsistent cross sectional associations of neighbourhood socioeconomic characteristics with depressive symptoms once personal socioeconomic factors were taken into account. Personal income, however, was strongly and inversely associated with CES-D score in all race and gender groups, most strongly in black people, and there was no evidence that neighbourhood context modified these associations. Neighbourhood ethnic density was not consistently related to depressive symptom score once socioeconomic factors were taken into account. Further elucidation of the relation between residential environments and depressive symptoms will require longitudinal analyses of the development of depressive symptoms that focus on the investigation of specific neighbourhood attributes.

\section{ACKNOWLEDGEMENTS}

Our thanks to Karen Matthews for her comments on an earlier version of this manuscript.

\section{Authors' affiliations}

C Henderson, Health Services Research Department, Institute of

Psychiatry, London, UK

A V Diez Roux, University of Michigan Center for Social Epidemiology and Population Health, USA

D R Jacobs Jr, Division of Epidemiology, School of Public Health, University of Minnesota, USA and Department of Nutrition, University of Oslo, Oslo, Norway

C I Kiefe, Division of Preventive Medicine, University of Alabama at Birmingham, and Birmingham Veterans Affairs Medical Center, USA

D West, University of Arkansas Medical Sciences, USA

D R Williams, University of Michigan Institute for Social Research, USA

Funding: this work was supported in part by grant MD00206 P60 (Dr Diez Roux) from NCMH (NIH). The CARDIA study was supported by NHLBI contracts N01-HC-48047, N01-HC-48048, N01-HC-48049,

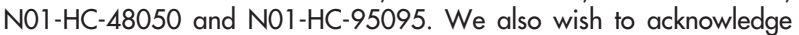
support from the MacArthur Network on Socioeconomic Factors and Health.

Competing interests: none declared.

\section{REFERENCES}

1 Pickett KE, Pearl M. Multilevel analysis of neighborhood socioeconomic context and health outcomes: a critical review. J Epidemiol Community Health 2001;55:111-22

2 Diez Roux AV. Investigating area and neighborhood effects on health. Am J Public Health $2001 ; 91: 1783-9$

3 Weich S Lewis $G$, Jenkins SP. Income inequality and the prevalence of common mental disorders in Britain. Br J Psychiatry 2001;178:222-7.

4 Sturm R, Gresenz CR. Relations of income inequality and family income to chronic medical conditions and mental health disorders: national survey. BMJ 2002;324:20-5.

5 Duncan C, Jones K, Moon G. Psychiatric morbidity: a multilevel approach to regional variations in the UK. J Epidemiol Community Health 1995;49:290-5.

6 Neeleman J, Wessely S. Ethnic minority suicide: a small group are study in South London. Psychol Med 1999;29:429-36.

7 Silver E, Mulvey EP, Swanson JW. Neighborhood structural characteristics and mental disorder: Faris and Dunham revisited Soc Sci Med 2002; 55: 1457-70.

8 Ross C. Neighborhood disadvantage and adult depression. J Health Soc Behav 2000;41:177-87.

9 Yen IH, Kaplan GA. Poverty are residence and changes in depression and perceived health status: evidence from the Alameda County study. Int J Epidemiol 1999;28:290-5

10 Reijneveld SA, Schene AH. Higher prevalence of mental disorders in socioeconomically deprived urban areas in the Netherlands: community or personal disadvantage? J Epidemiol Community Health 1998;52:2-7.

11 Klebanov PK, Brooks-Gunn J, Duncan G. Does neighborhood and family poverty affect mothers' parenting, mental health and social support? Journal of Marriage and Family 1994;56:441-55.
12 Driessen G, Gunther N, Van Os J. Shared social environment and psychiatric disorder: a multilevel analysis of individual and ecological effects. Soc Psychiatry Psychiatr Epidemiol 1998;33:606-12.

13 Halpern, D. Minorities and mental health Soc Sci Med 1993:36:597-607.

14 Bell W. The utility of the Shevky typology for the design of urban sub-area studies. J Soc Psychol 1958;67:71-83.

15 Weschler H, Pugh TF. Fit of individual and community characteristics and rates of psychiatric hospitalisation. American Journal of Sociology 1967;73:331-8.

16 Rosenberg $M$. The dissonant religious context and emotional disturbance. American Journal of Sociology 1962;68:1-10.

17 Cairns E. Social class, psychological well-being and minority status in Northern Ireland. Int J Soc Psychiatry 1988;35:231-6.

18 Faris RE, Dunham HW. Mental disorders in urban areas; an ecological study of schizophrenia and other psychoses. Chicago: University of Chicago Press, 1939.

19 Mintz NL, Schwartz DT. Urban ecology and psychosis: community factors in the incidence of schizophrenia and manic depression among Italians in Greater Boston. Int J Soc Psychiatry 1964;10:101-18.

20 Levy L, Rowitz L. The ecology of mental disorder. New York: Behavioral Publications, 1973.

21 Muhlin GL. Mental hospitalisation of the foreign-born and the role of cultural isolation. Int J Soc Psychiatry 1979;25:595-605.

22 Rabkin JG. Ethnic density and psychiatric hospitalization: hazards of minority status. Am J Psychiatry 1979;136:1562-6.

23 Boydell J, van Os J, McKenzie K, et al. Incidence of schizophrenia in ethnic minorities in London: ecological study into interactions with environment. BMJ 2001;323:1336-8

24 Neeleman J, Wilson-Jones C, Wessely S. Ethnic density and deliberate self harm; a small area study in south east London. J Epidemiol Community Health 2001;55:85-90.

25 Halpern D, Nazroo J. The ethnic density effect: results from a national community survey of England and Wales. Int J Social Psychiatry 1999;46:34-46.

26 Friedman GD, Cutter GR, Donahue R, et al. CARDIA: study design, recruitment, and some characteristics of the examined subjects. J Clin Epidemiol 1988;41:1105-16.

27 Weissman MM, Sholomskas D, Pottenger M, et al. Assessing depressive symptoms in five psychiatric populations: a validation study. Am J Epidemiol 1977;106:203-14.

28 Diez Roux AV, Kiefe Cl, Jacobs DR, et al. Area characteristics and individuallevel socioeconomic position indicators in three population-based epidemiologic studies. Ann Epidemiol 2001;11:395-405.

29 Borrell LN, Diez Roux AV, Rose K, et al. Atherosclerosis risk in communities study. Neighbourhood characteristics and mortality in the atherosclerosis risk in communities study. Int J Epidemiol 2004;33:398-407.

30 Diez Roux AV, Merkin SS, Hannan P, et al. Area characteristics, individuallevel socioeconomic indicators, and smoking in young adults: the coronary artery disease risk development in young adults study. Am J Epidemiol 2003; 157:315-26.

31 Diez Roux AV, Merkin SS, Arnett D, et al. Neighborhood of residence and incidence of coronary heart disease. N Engl J Med 2001;345:99-106.

32 Diez-Roux AV, Nieto FJ, Caulfield L, et al. Neighbourhood differences in diet: the atherosclerosis risk in communities (ARIC) study. J Epidemiol Community Health 1999;53:55-63.

33 Waitzman NJ, Smith KR. Phantom of the area: poverty-area residence and mortality in the United States. Am J Public Health 1998:88:973-6 (Erratum in Am J Public Health 1998;88:1122)

34 Ellaway A, Anderson A, Macintyre S. Does area of residence affect body size and shape? Int J Obes Relat Metab Disord 1997;21:304-8.

35 Hart C, Ecob R, Davey Smith G. People, places and coronary heart disease risk factors: a multilevel analysis of the Scottish heart health study archive. Soc Sci Med 1997; 45:893-902.

36 Ellaway A, Macintyre S. Does where you live predict health related behaviours? : a case study in Glasgow, Health Bull (Edinb) 1996:54:443-6.

37 Stokols D, Allen J, Bellingham RL. The social ecology of health promotion: implications for research and practice. Am J Health Promot 1996; 10:247-51.

38 Davey Smith G, Hart C, Watt G, et al. Individual social class, area-based deprivation, cardiovascular disease risk factors, and mortality: the Renfrew and Paisley study. J Epidemiol Community Health 1998;52:399-405.

39 Halpern D. Introduction and background. In: Mental health and the built environment. London: Taylor and Francis, 1995:1-27.

40 Wandersman A, Nation M. Urban neighborhoods and mental health. Am Psychol 1998;53:647-56

41 Klinenberg E. Heat wave: a social autopsy of disaster in Chicago. Chicago: University of Chicago Press, 2002.

42 Duncan G, Raudenbush SW. Assessing the effects of context in studies of child and youth development. Educational Psychologist 1999;34:29-41.

43 Diez Roux AV. Estimating neighborhood health effects: the challenges of causal inference in a complex world. Soc Sci Med 2004;58:1953-60.

44 Bingenheimer JB, Raudenbush SW. Statistical and substantive inferences in public health: issues in the application of multilevel models. Annu Rev Public Health 2004;25:53-77.

45 Snijders TAB, Bosker RJ. Multilevel analysis: an introduction to basic and advanced multilevel modeling. London: Sage, 1999.

46 Dalgard OS, Tambs K. Urban environment and mental health. Br J Psychiatry 1997; 171:530-6. 